\title{
25 years of the IPCC
}

1st science assessment

2nd

THE INTERGOVERNMENTAL PANEL ON CLIMATE CHANGE (IPCC) was founded 25 years ago to provide authoritative assessments on thle emerging problem of climate change. Since its first report in 1990, the IPCC has
issued increasingly complex follow-ups about every six years. The climate models that feed into the assessments have grown bigger and better, but researchers have not succeeded in reducing some key uncertainties about climate change.

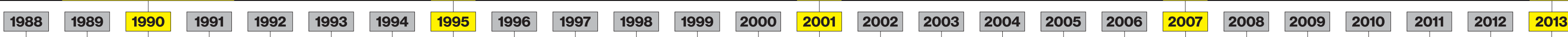

\begin{tabular}{|c|c|c|c|}
\hline $\begin{array}{l}\text { GETTING BIGGER } \\
\text { The IPCC's Working Group I } \\
\text { report on the science of } \\
\text { climate change has more } \\
\text { thate }\end{array}$ & & $\begin{array}{l}\text { REPORT PAGES } \\
\text { Each paper ream } \\
\text { represents } 50 \text { pages. }\end{array}$ & \\
\hline $\begin{array}{l}\text { The newest, due later in } \\
\text { September, drew } 52,822 \\
\text { comments in response to its } \\
\text { first and second drafts. } \\
\text { Source: }\end{array}$ & $\begin{array}{l}\text { iịiiiiiiiiiiiii } \\
\text { iịiiiiiiiiiiiii } \\
\text { iiiiiii }\end{array}$ & $\begin{array}{l}\text { LEAD AUTHORS Count does not } \\
\text { include contributing authors, who } \\
\text { often number many hundreds more. }\end{array}$ & 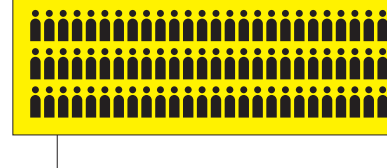 \\
\hline
\end{tabular}

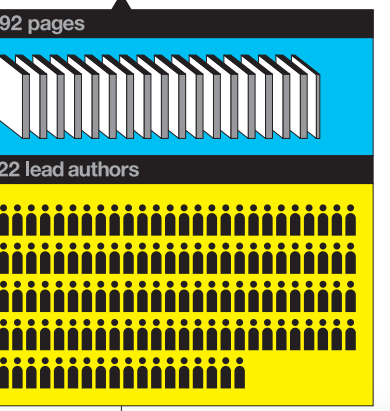

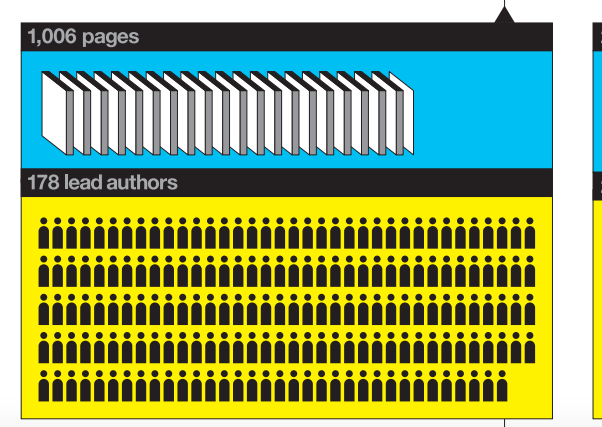

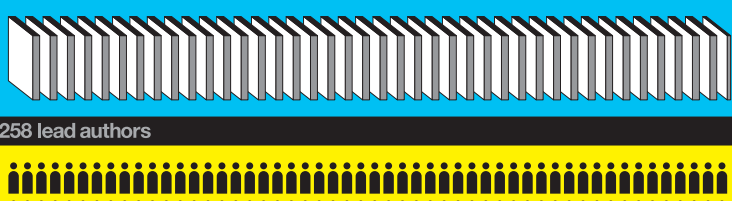

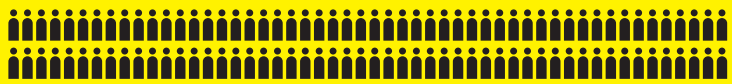

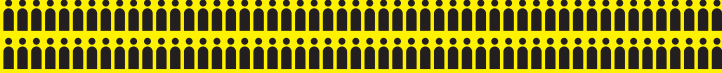

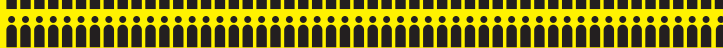

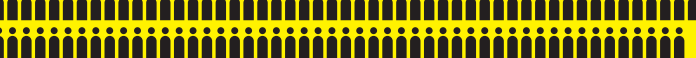

th Source: IPCC
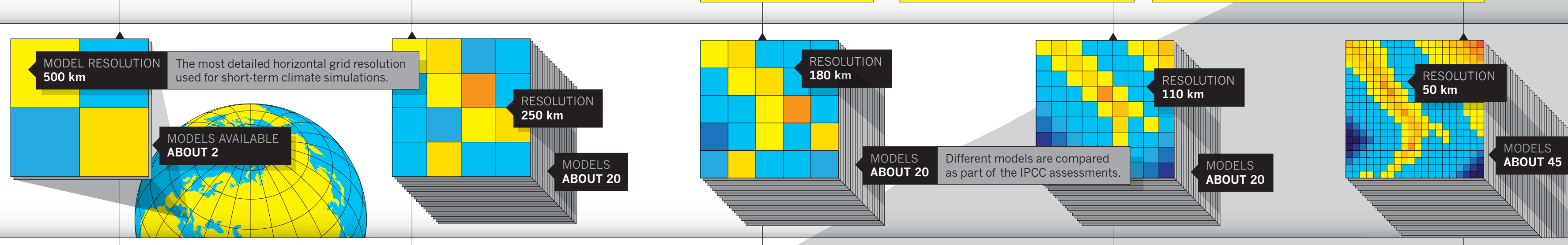

\section{UNEVEN PROGRESS \\ Researchers have made \\ no gains in narrowing the
estimate of climate sensitivi 2 ? \\ how much the world is likely
to warm if fatmospheric \\ lo warm if atmospheric
$\mathrm{CO}_{2}$ levels double from the \\ preindustrial value of 270 parts
per million (p.p.m.). But the \\ accurate at simulating the
current climate. Source: IPCC}

GAINING

CONFIDENCE

Successive IPCC reports
have grown more definitive
in identifying humans as the

cause of much of the recent
cus the
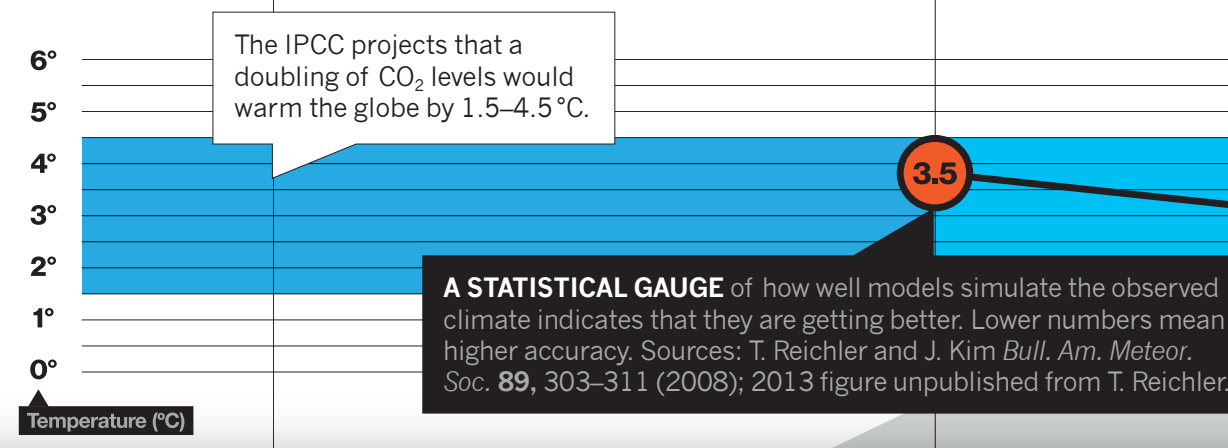

IPCC established.

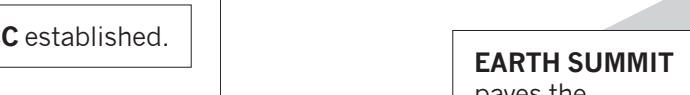

\begin{tabular}{l|l|}
\hline 1ST ASSESSMENT REPORT \\
"Emissions resulting from human
\end{tabular}

"Emissions resulting from human treaties limiting \begin{tabular}{|l|l|}
\begin{tabular}{l|l} 
activities are substantially \\
increasing the atmospheric
\end{tabular} & $\begin{array}{l}\text { greenhouse-gas } \\
\text { emissions. }\end{array}$ \\
\hline
\end{tabular} enhance the greenhouse
resulting on average in a
additional warming."

additional warming:" concentrations of the greenhouse
gases... These increases will
enhance the greenhouse effect.
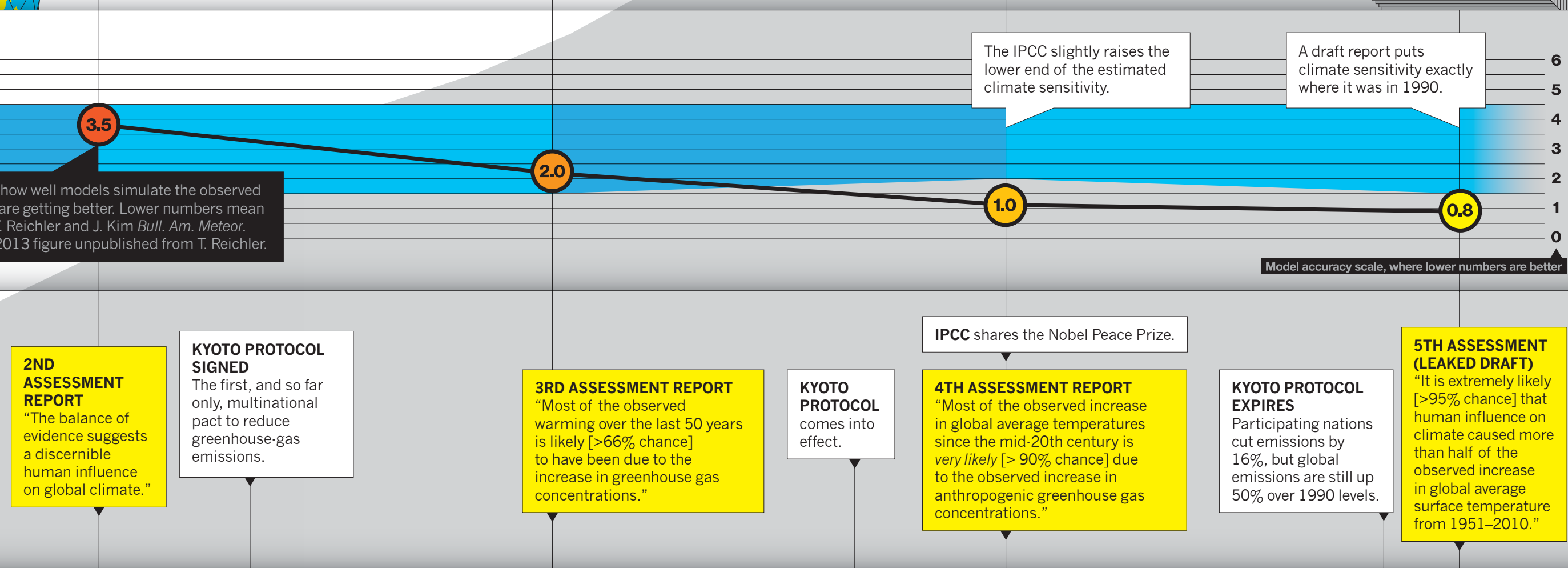

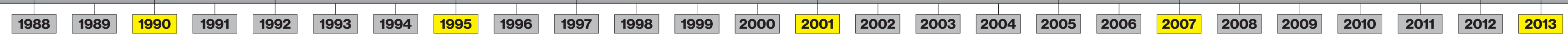
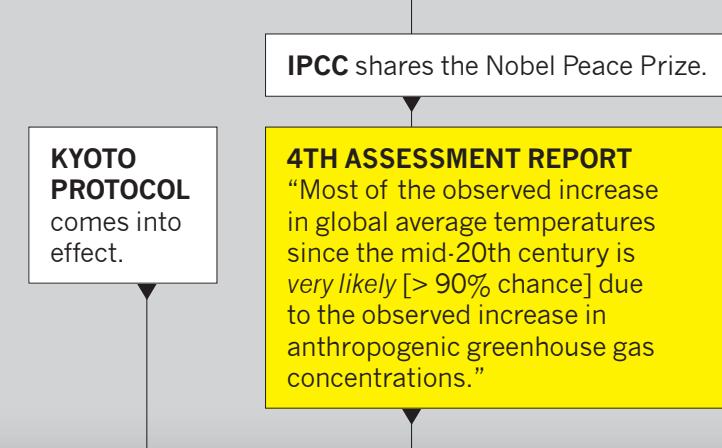
4TH ASSESSMENT REPORT "Most of the observed increase
in global average temperatures in global average temperature
since the mid. 20 th century is
very likely [ $[>90 \%$ chance] due
to the observed increase in to the observed increase in
anthropogenic greenhouse gas
concentrations."

KYOTOP POT
EXPRES
Participa

Participating na
cut emissions by \begin{tabular}{|l|l|l} 
& hXrticipating nations & human influence on \\
climate caused mor \\
cut emissions by \\
$16 \%$, but global & than half of the \\
emissions are still up & observed increase \\
$50 \%$ over 1990 levels. & in global average
\end{tabular} Warming over the last 50
is likely [> $>6 \%$ chances
to have been due to the
increase in greenhouse increase in greenhouse gas
concentrations."
3RD ASSESSMENT REPORT 